\title{
Percepções de gestantes com diabetes mellitus gestacional: diagnóstico, hospitalização e enfrentamentos
}

\author{
Perceptions of pregnant women with gestational diabetes mellitus: diagnosis, \\ hospitalization and confrontation
}

\section{Percepciones de las gestantes con diabetes mellitus gestacional: diagnóstico, hospitalización y enfrentamientos}

\author{
Recebido: 19/08/2019 \\ Aprovado: 04/03/2020 \\ Publicado: 01/07/2020
}

\author{
Maira Julyê Mota Fernandes ${ }^{1}$ \\ Cintia Bragheto Ferreira ${ }^{2}$
}

Este é um estudo qualitativo-descritivo realizado em 2018, num hospital universitário goiano, e que tem como objetivo investigar como gestantes com diabetes mellitus gestacional vivenciaram o diagnóstico e a internação e identificar as estratégias de coping para o enfrentamento da doença. Realizaram-se entrevistas semiestruturadas com seis gestantes. A análise dos dados foi indutiva, a partir da transcrição na íntegra e leitura curiosa e exaustiva das entrevistas, organizadas a posteriori em eixos temáticos, analisados embasados nas doenças crônicas, gestantes e coping. Emergiram quatro temáticas: Percepções sobre o diagnóstico; Vivências relacionadas à internação; Estratégias de enfrentamento; e, Relações entre emoções e diabetes mellitus gestacional. Verificou-se sentimentos como ansiedade e angústia frente ao diagnóstico e dificuldades com mudanças alimentares na hospitalização. As principais estratégias de enfrentamento relacionaram-se ao autocuidado e suporte social/familiar. Nos aspectos emocionais, não houve consenso que seja fator determinante para alterações na enfermidade. Descritores: Diabetes gestacional; Adaptação psicológica; Hospitalização; Complicações na gravidez; Emoções.

This is a qualitative-descriptive study conducted in 2018, at a university hospital in the state of Goiás, which aims to investigate how pregnant women with gestational diabetes mellitus experienced their diagnosis and hospitalization and to identify coping strategies for dealing with the disease. Semistructured interviews were conducted with six pregnant women. Data analysis was inductive, from the full transcription and curious and exhaustive reading of interviews, later organized in thematic axes and analyzed based on chronic diseases, pregnant women and coping. Four themes emerged: Perceptions about the diagnosis; Experiences related to hospitalization; Coping strategies; and Relationships between emotions and gestational diabetes mellitus. There were feelings such as anxiety and anguish regarding the diagnosis and difficulties with dietary changes during hospitalization. The main coping strategies were related to self-care and social/family support. Regarding emotional aspects, there was no consensus that it is a determining factor for changes in the disease.

Descriptors: Diabetes, Gestational; Adaptation, Pychological; Hospitalization; Pregnancy complications; Emotions.

Este es un estudio cualitativo-descriptivo realizado en 2018 en un hospital universitario de Goiás, que tiene por objeto investigar la forma en que las mujeres embarazadas con diabetes mellitus gestacional experimentaron el diagnóstico y la hospitalización e identificar las estrategias de coping para hacer frente a la enfermedad. Se realizaron entrevistas semiestructuradas a seis mujeres embarazadas. El análisis de los datos fue inductivo, basado en la transcripción completa y en la lectura curiosa y exhaustiva de las entrevistas, organizadas después en ejes temáticos, analizadas en base a las enfermedades crónicas, las mujeres embarazadas y coping. Surgieron cuatro temas: Percepciones sobre el diagnóstico; Experiencias relacionadas con la hospitalización; Estrategias de enfrentamiento; y, Relaciones entre las emociones y la diabetes mellitus gestacional. Hubo sentimientos como la ansiedad y la angustia ante el diagnóstico y dificultades con los cambios de dieta en la hospitalización. Las principales estrategias de enfrentamiento estuvieron relacionadas con el autocuidado y el apoyo social y familiar. En los aspectos emocionales, no hubo consenso de que es un factor determinante para cambios en la enfermedad.

Descriptores: Diabetes gestacional; Adaptación psicológica; Hospitalización; Complicaciones del embarazo; Emociones.

1. Psicóloga. Especialista em Saúde Materno Infantil. Mestranda pelo Programa de Pós-Graduação em Psicologia (PPGP) da Universidade Federal do Triângulo Mineiro (UFTM), Uberaba, MG, Brasil. ORCID: 0000-0002-5107-6000

E-mail:

mairajulye@gmail.com

2. Psicóloga. Mestre e Doutora em Enfermagem em Saúde Pública. Professora Adjunta no Departamento de Psicologia e do PPGP/UFTM,

Uberaba, MG, Brasil. ORCID: 0000-0003-4070-7169 E-mail: cintiabragheto@gmail.com 


\section{INTRODUÇÃO}

$\mathbf{E}$

m nível mundial, estima-se que 425 milhões de indivíduos, com idade entre 20 e 79 anos possuam algum tipo de diabetes mellitus ${ }^{1}$. Considerando a mesma faixa etária, o Brasil ocupa a $4^{\mathrm{o}}$ posição no ranque mundial com maiores taxas de diabetes mellitus em sua população adulta, estimando-se 14,3 milhões de pessoas ${ }^{1}$.

Essas estimativas estão relacionadas, principalmente, às condições econômicas tendo em vista o seu aumento verificado nos países que estão em transição de baixa para renda média e, também, estão associadas ao crescimento populacional e ao envelhecimento ${ }^{1}$. Em 2030 , a diabetes poderá vir a ser a sétima causa de morte no mundo ${ }^{2}$. Estima-se, ainda, que em se tratando da diabetes mellitus gestacional (DMG), a cada 10 gestantes, uma ou duas terão a doença ${ }^{3}$.

A DMG corresponde à hiperglicemia diagnosticada na gravidez, que pode ou não permanecer após o parto, devendo ser avaliada e controlada, em virtude de poder ocasionar comprometimento gestacional ${ }^{4}$. Os altos índices dessa enfermidade, nos últimos 20 anos, podem relacionar-se também a questões étnicas, obesidade e sedentarismo, devendo deste modo, ser avaliada e controlada 4,5 .

Considerando os fatores de risco perinatais relacionados à diabetes e seus desfechos, uma pesquisa realizada com 201 gestantes portadoras de diabetes tipo 1, tipo 2 e DMG, acompanhadas em um ambulatório de pré-natal de alto risco, demonstrou maior ocorrência de parto cesárea, prevalência de prematuridade, seguida de macrossomia e má formação fetal ${ }^{6}$. Por isso, destaca-se a importância em não subestimar a prevalência de hiperglicemia na gestação.

Para as gestantes, possuir DMG representa fator de risco para o desenvolvimento posterior de diabetes tipo 2 ou intolerância a glicose após o parto ${ }^{3}$. Deste modo, a hiperglicemia na gravidez configura-se como problema de saúde que necessita de atenção ${ }^{6}$, pois a gestação, apesar de ser considerada uma experiência normal do desenvolvimento humano, é um período de transição marcado por grandes transformações, não só físicas como psíquicas ${ }^{7}$. Contudo, fatores de risco gestacionais predisponentes para o desenvolvimento da diabetes podem ser identificados na consulta de pré-natal, representando assim auxílio no cuidado dessa população ${ }^{8}$.

As repercussões emocionais da gravidez tendem a estar associadas a sentimentos ambivalentes e contraditórios, tais como insegurança e medo ${ }^{9}$. Em se tratando de gestantes com DMG esses sentimentos tendem a se somar às preocupações relacionadas à doença, como a angústia com o que possa vir a acontecer com ela mesma e com o bebê ${ }^{9}$. Além disso, as gestantes com DMG necessitam se adaptar às mudanças na rotina alimentar e monitoramento constante da glicemia ${ }^{9}$, podendo este novo contexto representar uma situação estressora.

O coping demonstra-se importante na vivência da diabetes por gestantes e pode ser conceituado como: conjunto de esforços do indivíduo na criação de estratégias e/ou recursos para lidar com condições adversas ${ }^{10}$.

O coping pode ser constituído por determinantes variados e representa a tentativa de ajustamento pessoal a obstáculos ameaçadores dos recursos adaptativos do sujeito ${ }^{10}$. Além disso, são estratégias utilizadas frente a circunstâncias diante das quais não se possui preparação, controle e conhecimento prévio $^{10}$, configurando-se como um conjunto de esforços frente a eventos estressores que promovem no indivíduo a necessidade de elaborar uma forma de enfrentamento. Tais estratégias podem modificar-se ao longo do tempo, variando de acordo com as experiências pessoais e o estágio de vida ${ }^{11}$.

As estratégias de coping podem ser classificadas em dois grandes grupos: aquelas com foco na emoção e as com foco no problema. Estratégias focadas na emoção correspondem à construção de mecanismos para regulação de respostas emocionais provocadas por um evento estressor. As estratégias focadas no problema visam agir diretamente na fonte que ocasiona o estresse, buscando mudá-lo e/ou solucioná-lo10.

As práticas voltadas a DMG configuram-se como importante fator de proteção e auxílio, considerado que a vivência da enfermidade juntamente com a gestação pode promover variados 
sentimentos e experiências capazes de causar sofrimento ${ }^{4}$. Neste contexto, o presente estudo justifica-se ao buscar a ampliação da compreensão do conhecimento acerca da vivência da DMG.

Considera-se o aumento da incidência e prevalência da DMG em gestantes, e que a diabetes é capaz de causar repercussões físicas e emocionais importantes nessa população, como também complicações de longo prazo para mãe e bebê, além de fatores psicossociais e afetivos que devem ser considerados na adesão ao tratamento ${ }^{12}$. Assim, este estudo tem como objetivo investigar como gestantes com diabetes mellitus gestacional vivenciaram o diagnóstico e a internação e identificar as estratégias de coping para o enfrentamento da doença.

\section{MÉTODO}

Este é um estudo qualitativo-descritivo com mulheres internadas em uma maternidade de alto risco de um hospital universitário goiano, que possuíam o diagnóstico de DMG. 0 referido hospital funciona em regime de pronto-socorro, com o intuito de atender urgências e emergências referendadas pelas unidades de saúde do município onde os dados foram coletados.

Como critérios de inclusão, foram consideradas as pacientes maiores de 18 anos, que tiveram a diabetes desenvolvida durante a gravidez, estavam cientes do diagnóstico, conscientes e orientadas durante a internação, bem como condições de se locomover até a sala de entrevista, e com interesse em participar da pesquisa.

As informações foram coletadas entre maio e junho de 2018. 0 instrumento utilizado foi a entrevista, orientada por um roteiro semiestruturado, que abordou os dados sociodemográficos das participantes, assim como suas percepções acerca do diagnóstico da diabetes, os aspectos emocionais envolvidos, assim como o enfrentamento da doença e da internação para controle da diabetes.

A coleta de dados iniciou-se com a leitura das papeletas da maternidade para a identificação das pacientes com DMG internadas. Posteriormente, houve a abordagem de cada paciente no leito de internação. A partir disso, cada paciente foi convidada individualmente a participar da pesquisa através de entrevista individual, que foram audiogravadas e realizadas na sala destinada a atendimento psicológico individual da maternidade.

Optou-se pela quantidade de entrevistadas fundamentando-se no critério de saturação dos dados $^{13}$. As participantes foram nomes fictícios.

As entrevistas foram transcritas na íntegra, lidas com curiosidade ${ }^{14}$, compreendidas enquanto interesse genuíno pela riqueza dos detalhes das falas, de forma exaustiva ${ }^{15}$ e detalhada, o que resultou na construção, a posteriori, de quatro eixos temáticos que descreviam as percepções das participantes frente aos momentos da diabetes.

Os eixos temáticos foram analisados embasados na teoria de coping, ancorada na perspectiva das estratégias de enfrentamento com foco na emoção e com foco no problema. As estratégias de coping representam a tentativa de ajustamento pessoal a obstáculos ameaçadores aos recursos adaptativos dos indivíduos ${ }^{10}$.

Buscou-se contemplar as diretrizes e as normas de regulamentação em pesquisas envolvendo seres humanos, sendo o projeto submetido e aprovado por um Comitê de Ética em Pesquisa, sob o parecer $\mathrm{n}^{\circ}$ 2.631.379. Por meio do Termo de Consentimento Livre e Esclarecido (TCLE), foram informados às participantes os objetivos da pesquisa, as implicações da participação e o consequente anonimato, além da possibilidade de desistência a qualquer momento, sem qualquer prejuízo para o tratamento recebido no âmbito hospitalar.

\section{RESULTADOS}

Houve a participação de seis mulheres que receberam nomes fictícios de flores: Violeta, Orquídea, Rosa, Tulipa, Camélia e Jasmim. 
A respeito da caracterização sociodemográfica das participantes, identificou-se que a média de idade foi de 34,6 anos, variando entre 30 e 42 anos. Em relação à escolaridade, duas (Violeta e Rosa) possuíam ensino superior completo, enquanto que as demais declararam ensino médio completo.

Sobre o trabalho, as atividades citadas foram: servidora municipal (Violeta), diarista (Orquídea), pedagoga e do lar (Rosa), cozinheira (Tulipa), costureira (Camélia) e recepcionista hospitalar (Jasmim). Em relação ao estado civil, quatro relataram ser casadas legalmente (Orquídea, Rosa, Tulipa e Camélia) e duas moravam junto com o companheiro (Violeta e Jasmim). Em relação à religião a maior parte das entrevistadas referiu ser evangélica.

No momento de realização das entrevistas todas se encontravam no terceiro trimestre de gestação, e com idade gestacional entre 28 semanas e 06 dias, até 40 semanas e 01 dia. 0 tempo de diagnóstico da DMG esteve compreendido entre 05 dias e 21 semanas. Dentre as participantes, Orquídea e Jasmim já haviam passado pela experiência do diagnóstico de DMG em gravidez anterior.

Emergiram das entrevistas quatro temáticas: 1) Percepções sobre o diagnóstico; 2) Vivências relacionadas à internação; 3) Estratégias de enfrentamento; e, 4) Relações entre emoções e diabetes mellitus gestacional.

\section{Percepções sobre o diagnóstico}

Para as entrevistadas, a percepção do diagnóstico esteve relacionada à dificuldade em reconhecer-se como doente, verificado nas falas:

Quando a dra J. falou que eu tava com diabete, eu falei assim uai, diabete? Eu magrinha desse jeito, né? (aponta para o próprio corpo). (Rosa)

Pra mim é novidade, né, porque eu nunca internei por conta de diabete, né, ainda mais que eu pensava que tinha mais a ver com peso, no início eu pensei que eu tinha feito o exame errado (risos), porque no dia que eu fiz a primeira coleta que deu alterado eu não tinha reparado que eu tinha glicemia em jejum e eu tinha tomado um iogurte, né, aí eu pensei que tinha sido por causa disso, mas aí depois eu repeti e continuou assim. (Jasmim)

Sobre a expressão de sentimentos, foram relatados ansiedade, angústia e medo:

Me deu medo, né, porque diabete já é algo muito ruim, é uma doença muito grave, muito séria, fiquei com medo, mais pelo bebê mesmo, porque prejudica mais a ele, né. (Jasmim)

No começo eu fiquei assim meio assustada, eu não sabia como é que era, mas depois foi normal assim, só controlar mesmo. (Tulipa)

Sei lá, milhões de coisa, que a minha gestação não ia pra frente, um monte de coisa. (Camélia)

[...] a gente fica com medo também, né, não sabe nem o que tá esperando a gente lá na frente, aí cê chega no hospital e fica escutando um monte de coisa das meninas que já estão aí, de algumas que perderam, igual essa semana nasceu um menininho morto, aí você fica com medo, né. (Camélia)

As repercussões do diagnóstico da DMG também estiveram relacionadas à queixa frente à alimentação limitada:

Eu fiquei meio assustada, eu sou muito viciada em chocolate e agora eu não posso comer (risos). (Jasmim)

Ainda como parte das percepções do diagnóstico, algumas das gestantes demonstraram possuir atenção e conhecimento frente ao adoecimento por diabetes, relatando as possíveis complicações da enfermidade para o bebê:

Pra mãe não tem problema nenhum, a criança que pode ficar grande demais, pesada e na hora do parto ter complicação e futuramente desenvolver a diabetes mesmo. (Violeta)

Eu pensei logo no A., falei nossa ele pode nascer cego, pode nascer com problema, eu penso logo no bebê. (Tulipa)

A questão genética aparece como fator importante para o desenvolvimento da doença:

Geralmente os médicos fala que se tem caso na família, cê tem 50\% de chance de desenvolver. (Violeta)

Aí eu pensei deve, né, por a minha mãe ter e minha avó tinha, que ela faleceu, deve ser alguma coisa relacionada, vai passando de geração a geração. (Rosa)

Acerca da reincidência da doença e suas expressões de tranquilidade aparece:

Normal. Igual eu te falei, não sofro não. Eu sei, eu já sabia, né, já passei por isso outras duas vezes. (Orquídea)

Eu já tive diabetes gestacional na primeira gravidez só que eu não precisei me internar não, com a dieta em casa mesmo tá bom. (Jasmim) 


\section{Vivências relacionadas à internação}

As emoções relatadas estiveram associadas a sentimentos como ansiedade, insegurança e culpabilização:

Fiquei ansiosa sem saber como que seria, porque eu nunca tinha entrado no hospital pra ficar internada. (Violeta) Como é? Ai sei lá, nunca fui internada assim, muito ruim. (Camélia).

Tem hora que dá aquela vontade de ir embora, aí você olha pro outro lado e pensa não, se for e depois acontecer alguma coisa eu vou me sentir culpada, eu tô aqui, melhor tá aqui, é ruim mais é melhor do que ficar em casa e acontecer coisa pior, né. (Tulipa)

Muita preocupação. Aí junta também quando a neném não mexe, aí eu penso meu Deus, será que tá sofrendo, será quê que tá acontecendo e quando como uma coisa assim que pesa na consciência nossa não deveria ter comido, não ter tomado um pouquinho de refrigerante, aí ela não mexe e eu falo meu Deus, matei minha filha, aí ela não mexe e eu fico cutucando até ela mexer. (Rosa)

Também foi relatado o período de afastamento dos familiares e às constantes preocupações com os entes queridos:

[...] só preocupação, né, assim, só o que me deixa preocupar com meus filhos que tá lá sem mim. (Orquídea) Já fiquei chorosa porque meus filhos não podem vir (risos). (Jasmim)

Horrível (risos). Muito ruim, ficar sem o marido da gente, sem o filho da gente. (Camélia)

[...] sem poder contar que eu tô sozinha, meu marido não pode ficar, não pode ter mais gente no quarto. (Violeta)

A hospitalização também esteve relacionada a mudanças na rotina diária:

Faz todo sentido, se você colocar tudo ali juntinho, se você ver como é a sua vida em casa e como é a sua vida dentro de um hospital é totalmente diferente. No hospital você não estressa [...] você tá ali pra descansar, você tem tudo na mão, você tem comida, você tem um lugar limpo [...]. (Orquídea)

A primeira vez eu fiquei foi pra conhecimento que a nutricionista passou, aí foi me informar. A segunda vez eu não gostei não, nossa que comida ruim desse hospital, não, quero ir embora pra minha casa. A segunda eu achei ruim, aí agora essa terceira que eu já tava preocupada com o final da gestação [...]. (Rosa)

É uma rotina diferente que muda, né, você não tá acostumado com essa rotina, aqui não tem nada pra você fazer. (Tulipa)

Eu não entendi ainda porque que eu tô aqui não (risos). (Jasmim)

Considerando o tratamento, dificuldades com as restrições alimentares e o seguimento adequado da prescrição nutricional também foram relatadas:

[...] aqui é um cardápio diferente do que eu tô acostumada em casa [...]. (Tulipa)

Nossa assim, agora que tá mudando porque esse final de semana passado foi aniversário do meu filho, né, aí eu comi bolo, coisas que não podia (risos), mas tá sendo difícil, a dieta tá sendo difícil. (Jasmim)

Preocupações financeiras também estiveram presentes:

Eu diria que isso me preocupa muito, né, ainda mais pelo fato de que quando a gente tá aqui, a gente não tá ganhando dinheiro, né, mas eu tando em casa também não tô ganhando, não tô dando conta mais. Então assim, me preocupa. (Orquídea)

\section{Estratégias de enfrentamento}

As gestantes utilizaram o coping por estratégias focadas no problema e na emoção, além do suporte social e familiar para enfrentarem sua enfermidade, com atenção a alimentação e adoção de hábitos alimentares mais saudáveis:

[...] não adianta você ficar brigando, querendo comer tudo que não pode, porque não tem como. (Violeta)

A alimentação manda muito, que, às vezes, a gente não tem condições de fazer uma alimentação em casa igual a gente faz no hospital, horário é outra coisa que eu tenho certeza que faz diferença [...]. (Orquídea)

Mas eu também pensei na neném, se a mulher não seguir certinho pode ter problema pra neném, aí eu fiz a dieta [...]. (Rosa)

A primeira coisa que eu fiz, mudar meus hábitos alimentares. (Tulipa)

[...] mesmo não tendo passado a dieta pra mim eu por conta própria tirei algumas coisas que eu sei que não faz bem [...]. (Jasmim)

As estratégias de enfrentamento com foco na emoção voltaram-se para a valorização da internação para o autocuidado, além do não pensar, e do desejo de fuga do hospital:

[...] eu brinco que quando eu interno eu vou pro meu hotel Porque aqui eu não lavo, não passo, não arrumo, não cozinho, eu não cuido de criança, aqui eu realmente descanso, aqui eu realmente não descanso muito a mente, porque eu preocupo com eles, né, com os meus filhos, mas porém eu descanso meu corpo [...] eu procuro esquecer minha vida lá, eu procuro viver o aqui, porque se eu ficar aqui pensando lá, não fica bom [...]. (Orquídea)

Ultimamente eu tô caminhando, eu desço ali pra baixo fico um pouco, eu assisto TV, fico quieta. (Tulipa) 
Eu tento não ficar pensando lá em casa. Aí mesmo assim eu penso, porque eu fico preocupada com a minha menina, mais eu pensei, quando eu tô pensando demais aí eu vou mudar meu foco, sair, conversar, andar pra não ficar pensando muito. (Rosa)

Estão com o pai, mas tá lá chorando querendo que eu vou embora (risos). Aí ele já fica com medo de ficar mais tempo, ainda mais agora que me deram um pote desse tamanho pra fazer xixi eu falei assim vou embora (risos). (Jasmim)

Só o medo mesmo, vontade de ir embora, vontade de essa semana voa logo pra ela nascer logo. (Camélia)

Além das estratégias focadas no problema e focadas na emoção, estiveram presentes o suporte social e familiar, representado pelo apoio tanto social, formado por outras pacientes internadas, como o familiar, representado pela figura da mãe e do esposo:

É, eu converso com as meninas, cada um tem uma história diferente, e a gente acaba compartilhando. (Tulipa)

Se eu faço alguma coisa? Fico conversando com as meninas, só conversando mesmo, olhando o bebezinho das outras. (Camélia)

Sua mãe liga e fala que você tem que pensar positivo, seu marido fala, aí você começa a ficar mais assim, aí depois você vê que tem gente que tá pior que você, mas o medo fica ainda. (Camélia)

[...] porque se fosse pelo meu marido eu já tava lá em casa também (risos). Ele nunca ficou longe de mim, porque lá era ele que ficava de acompanhante. (Jasmim)

Como apoio também se notou a expectativa sobre o cuidado com o bebê, que parece ter sido utilizada como estratégia de enfrentamento para a vivência da internação e das repercussões da diabetes:

É, porque eu sei que ele estando aqui (aponta pra barriga), ele precisa de mim. E eu tô com ele e ele tá comigo. (Orquídea)

Pensando nele (aponta para a barriga), pensando no meu neném só, porque se eu for pensar nas coisas lá fora eu vou embora agora (risos), porque só tô aqui por causa dele mesmo, não é nem por causa de mim não é por causa dele. (Jasmim)

A religiosidade/espiritualidade também esteve presente nas falas das participantes, apresentando-se como aliada no enfrentamento da diabetes na gravidez:

Eu fico tranquila. Eu oro muito a Deus, pedindo pra ter uma boa hora, tá tranquilo. (Violeta)

Deus, ele acima de tudo (risos). Ele que é minha força, minha fortaleza, ele que me ajuda, que me guia, que me protege é nele que eu tenho força pra tudo. (Orquídea)

Eu leio muito a bíblia, né, aí eu gosto de procurar texto que me ajuda a fortalecer e saber que eu tenho que deixar na mão de Deus, pra que pela vontade dele vai ocorrer tudo bem. (Rosa)

\section{Relações entre emoções e diabetes mellitus gestacional}

Aqui apareceu o modo como as gestantes identificam uma possível relação entre o estado emocional e o descontrole glicêmico:

Assim é muita coisa, isso tudo afeta um pouco, e quando você me pergunta se eu acho que o psicológico tem a ver com o que eu passo, pra mim tem tudo a ver, porque quando eu estou bem psicologicamente eu estou bem em tudo [...]. (Orquídea)

Eu acho que tem, porque quando você tá alterada assim, preocupada igual mesmo o dia que o médico falou que eu tinha que ficar internada ela foi lá em cima! (Tulipa)

Contudo, outras demonstram a não relação entre o estado emocional e o descontrole glicêmico:

Acho que não. Não vejo. (Violeta).

Eu não sei, não sei te falar. (Camélia).

Os aspectos emocionais mostraram-se ainda relacionados com a autopercepção da fisiologia e do comportamento:

Tem hora que eu acho que é o emocional e tem hora que é assim, eu comi uma pizza e não aumentou, passei a noite toda chorando e ela foi pra quase 300 (risos). Aí que eu penso, será mesmo que é o emocional tudo isso que tá acontecendo? Tô em jejum e tá alto, eu passei raiva, aí fica, né, isso na cabeça, será que é, será que não é (risos). (Rosa)

Eu acho assim que é mais o meu controle emocional. Eu sou muito nervosa e quando eu fico nervosa eu como muito, aí é onde eu pego um doce que é o que me acalma, o chocolate (risos). (Jasmim) 


\section{DISCUSSÃO}

Considerando as experiências de uma gestação com diabetes uma investigação demonstrou que o diagnóstico proporcionou cuidado com a enfermidade, medo e culpa frente à utilização de medicamentos para controle da doença e, dificuldade em compreender as consequências do diagnóstico a médio e longo prazo ${ }^{16}$.

Outra pesquisa mostrou que o diagnóstico representou desafios e exigências às gestantes, além de um choque inicial e posterior equilíbrio ${ }^{17}$. Ainda noutro trabalho verificou-se o desejo por cuidado e atenção diante da enfermidade, bem como, sofrimento e preocupação frente ao diagnóstico, tratamento e falta de cuidado por parte dos profissionais de saúde, bem como houve queixas sobre a insuficiência de informações acerca da DMG para a referida população ${ }^{18}$. Tais pesquisas concordam com as participantes deste estudo ao relatarem ansiedade, angústia, medo e preocupação com o bebê. No diagnóstico ficou evidente que a diabetes é capaz de promover sentimentos e percepções variados em cada indivíduo que se descobre com a doença ${ }^{19}$.

O diagnóstico também despertou reflexões, desafios e exigências das gestantes. Evidenciou-se que as participantes tiveram dificuldade em enfrentar as mudanças inesperadas decorrentes do diagnóstico, mudanças essas representadas principalmente pela alimentação limitada, afastamento de familiares e/ou outros filhos e mudanças na rotina diária. Estes achados corroboram com outros achados acerca dos desafios diante do autocuidado de gestantes diabéticas, em que são expressos choque inicial diante do diagnóstico ${ }^{19,20}$.

Outras investigações apontam: que a enfermidade impacta de modo negativo a vida das gestantes ${ }^{21}$, sendo capaz de mudar a configuração familiar e alterar de maneira significativa a rotina e hábitos da gestante e seus familiares ${ }^{22}$, possibilidades de complicações para a gestante e o feto, desconhecimento das formas de acompanhamento e tratamento da $D M^{19,23}$, o que é concordante com a pesquisa aqui apresentada.

Mulheres com DMG tendem a enfrentar dificuldades para lidar com o autocuidado, principalmente relacionadas às restrições alimentares, além de sentirem alterações no sono e repouso decorrentes da gravidez, bem como lamentação frente a mudanças na rotina e prática de atividades diárias ${ }^{24}$. Neste estudo, as dificuldades com a alimentação possuíram destaque, concordante com estudo que apontou problemas com as restrições alimentares e o seguimento adequado da prescrição nutricional, relacionados à mudança de hábitos, apoio social e dificuldade em lidar com privações ${ }^{25}$.

Nas dificuldades enfrentadas para a adesão ao tratamento de DMG aponta-se que é preciso conscientização e incentivo a participação em programas educativos, com uma equipe multiprofissional, e que estes espaços possam favorecer aspectos subjetivos do adoecer, para além do quadro patológico ${ }^{12}$. Deste modo, a construção e manutenção de um novo estilo de vida deve partir da ideia de que cada gestante é única, sendo necessário compreender seu contexto social, afetivo e cultural para a adesão ao tratamento, favorecendo o cuidado ${ }^{12,20}$.

Por sua vez, o uso de medicações é recomendado apenas em casos em que é observado um crescimento excessivo do feto ou um alto descontrole glicêmico 5,15 . Apesar da proposta terapêutica utilizada para o controle da DMG ser eficiente, ela não exime, em muitos casos, a necessidade de internação da gestante. Essa internação pode ocorrer em vários períodos da gravidez, devido ao descontrole glicêmico, sendo de suma importância o acompanhamento da gestante por uma equipe multiprofissional ${ }^{6}$ que buscará estabelecer vínculos de confiança e segurança com as gestantes, para atenção e apoio às demandas ${ }^{20}$.

As gestantes deste estudo demonstraram preocupações comuns relacionadas à alimentação e afastamento de familiares e outros filhos. Uma hospitalização prolongada pode contribuir para a manifestação de conflitos emocionais e sentimentos de culpa, desamparo, cansaço e preocupação, principalmente vinculados a gestantes que possuam outros filhos pequenos que demandem cuidados maternos ${ }^{9}$. 
O sentimento de culpa é demonstrado sendo vinculado principalmente ao uso de medicações durante a gestação para controle da doença ${ }^{16}$. Nas mudanças ocorridas decorrentes da hospitalização, nota-se ainda a visão da internação como uma possibilidade de descanso, mas também, a impotência pela falta de mobilidade durante a internação.

A hospitalização também pode influenciar economicamente a unidade familiar, e a expectativa quanto às possíveis dificuldades financeiras que também é fator de alterações emocionais ${ }^{9}$.

As estratégias com foco no problema foram relacionadas à alimentação, voltadas então para práticas de nutrição adequadas. E, as estratégias com foco na emoção foram vinculadas à internação como forma de autocuidado, valorizando o espaço do hospital como capaz de promover atenção à doença e momentos de reflexão sobre o adoecimento. Outros recursos também destacados como importantes como o suporte social/familiar, as expectativas de cuidado, fuga/esquiva, como estratégias focadas na emoção, e a religiosidade/espiritualidade, concordam com outros trabalhos 9,22 .

Um estudo considerou a rede de apoio e o suporte emocional no enfrentamento da diabetes mellitus por gestantes, observou-se que a maioria fez uso de estratégias focadas no problema relacionado ao cuidado com a enfermidade durante a gestação fazendo acompanhamento com profissionais da saúde 22 .

Independente das estratégias de enfrentamento utilizadas pelo indivíduo para lidar com eventos estressantes, a satisfação e a validação da resposta do sujeito dependerá, principalmente, de sua flexibilidade e de sua disponibilidade para a mudança frente ao evento estressor. Além disso, novas condições de grande estresse solicitarão novo ajustamento pessoal aos obstáculos ameaçadores ${ }^{26}$.

A gestação em conjunto a uma enfermidade, como a diabetes, pareceu proporcionar singularidade especial em sua gestação. Sendo evidenciados sinais de sofrimento diante do contexto vivenciado4. As entrevistadas tiveram várias estratégias de enfrentamento que as auxiliaram a ampliar a percepção sobre o adoecimento e a necessidade de cuidado e autocuidado.

Sobre os aspectos emocionais, evidencia-se destaque no manejo de doenças crônicas, pelo fato das emoções poderem influenciar na estabilização e/ou na piora de muitas enfermidades, como no caso da diabetes. Nesse sentido, o suporte emocional e a utilização de estratégias de enfrentamento fazem parte do viver e conviver com doenças crônicas ${ }^{27}$.

Considera-se que as emoções também são importantes no cuidado das doenças crônicas, visto que possivelmente podem influenciar, tanto para a estabilização como na piora da enfermidade 27 , mesmo considerando que não houve consenso entre as participantes sobre se alterações emocionais influenciarem no descontrole glicêmico.

\section{CONCLUSÃO}

O diagnóstico despertou sentimentos como ansiedade, angústia e medo, além de dificuldade em compreender a DMG, no início, e de identificar-se com a doença, bem como os desafios proporcionados pelas alterações na alimentação e período de afastamento de familiares.

As estratégias com foco no problema estiveram representadas pelas mudanças alimentares, com o intuito de adesão ao tratamento, enquanto as estratégias com foco na emoção relacionaram-se à realização de atividades físicas breves como caminhar, falar sobre os sentimentos e a experiência de internação como alívio da ansiedade.

0 suporte familiar/social e a religiosidade/espiritualidade também corresponderam a importante fator para auxílio no autocuidado e vivência da internação. As emoções relacionaram-se à mudança de comportamento alimentar, como o constante desejo por alimentos não incluídos na dieta e o reflexo nas alterações glicêmicas. Todavia, não houve consenso de que as emoções sejam um fator determinante para o descontrole da glicemia. 
É preciso considerar que este estudo explorou apenas uma parcela da população de gestantes com o diagnóstico de DMG, internadas para controle da doença, residentes em um município de Goiás, tais aspectos podem representar uma limitação deste estudo, pois explorou as percepções de apenas seis gestantes hospitalizadas, não sendo deste modo, os dados passíveis de generalização.

Porém, os resultados encontrados oportunizaram um relevante conhecimento das dificuldades vivenciadas pelas gestantes diabéticas durante internação e, visibilidade da percepção dessas mulheres sobre o acometimento por uma doença no período gestacional, seu processo de enfrentamento, e ainda as mudanças desencadeadas pela internação. Tais achados representam conhecimento no atendimento das necessidades de saúde das mulheres com DMG.

Os sofrimentos causados pela vivência de uma gestação com diabetes poderiam ser minimizados com o fornecimento de informações sobre o assunto e apoio das equipes de saúde na valorização e acolhimento das inseguranças, medos e incertezas vivenciados neste período pelas gestantes, o que poderia promover mais segurança e fortalecimento das gestantes com DMG.

Também, é importante investimentos em pesquisas com gestantes vivenciando condições como a diabetes, que busquem favorecer as formas de conhecimento sobre a enfermidade e suas possíveis complicações e, estratégias de autocuidado adequadas. A valorização das vivências e percepções tem o intuito de ampliar as possibilidades das equipes de saúde em prestar assistência podendo fortalecer a atuação em saúde, de forma humanizada e sensível aos impactos e adversidades de uma gravidez com diabetes.

\section{REFERÊNCIAS}

1. International Diabetes Federation. IDF Diabetes Atlas [Internet]. Bruxelas: IDF; 2017 [citado em 01 maio de 2019]. Disponível em: https://www.diabetesatlas.org 2. World Health Organization. Diabetes [Internet]. Genebra: OMS; 2018 [citado em 01 maio de 2019]. Disponível em: https://www.who.int/en/news-room/fact-sheets/detail/diabetes

3. Organização Pan-Americana de Saúde. Dia mundial da saúde 2016: combater a diabetes [Internet]. São Paulo: OPAS; 2016 [citado em 10 maio de 2019]. Disponível em: https://www.paho.org/bireme/index.php?option=com_content\&view=article\&id=326:diamundial-da-saude-2016-combater-o-diabetes\&Itemid=183\&lang=pt

4. Organização Pan-Americana da Saúde, Ministério da Saúde (Brasil), Federação Brasileira das Associações de Ginecologia e Obstetrícia, Sociedade Brasileira de Diabetes. Rastreamento e diagnóstico de diabetes mellitus gestacional no Brasil [Internet]. Brasília, DF: Ministério da Saúde; 2017 [citado em 29 maio 2019]. 36p. Disponível em: https://www.diabetes.org.br/profissionais/images/pdf/diabetes-gestacional-relatorio.pdf

5. Carolan-Olah MC. Educational and intervention programmes for gestational diabetes mellitus (GDM) management: an integrative review. Collegian [Internet]. 2015 [citado em 05 fevereiro 2020]; 23(1):103-14. DOI: http://dx.doi.org/10.1016/j.colegn.2015.01.001

6. Moreno HP, Pinto FPF, Blask CAB, Souza CC, Guidone RGR, Toledo SF. Diabetes e gestação: estudo comparativo de variáveis maternas e perinatais. UNILUS Ens Pesqui. [Internet]. 2017 [citado em 10 jun 2019]; 14(35):105-15. Disponível em http://revista.unilus.edu.br/index.php/ruep/article/view/835

7. Maldonado MT. Psicologia da gravidez: gestando pessoas para uma sociedade melhor. São Paulo: Ideias \& Letras; 2017. 248p.

8. Ministério da Saúde (Br), Secretaria de Atenção à Saúde, Departamento de Ações Programáticas Estratégicas. Gestação de alto risco: manual técnico [Internet]. 5ed. Brasília, DF: Ministério da Saúde; 2010 [citado em 21 maio 2019]. 304p. Disponível em: http://bvsms.saude.gov.br/bvs/publicacoes/gestacao_alto_risco.pdf 
9. Costa IG. As percepções da gravidez de risco para a gestante e as implicações familiares. Rev Gaúch Enferm. [Internet]. 2002 [citado em 15 jul 2019]; 23(1):30-46. Disponível em: http://seer.ufrgs.br/RevistaGauchadeEnfermagem/article/view/4391

10. Lazarus RS, Folkman S. Stress, appraisal, and coping. New York: Springer Publishing Company; 1984. 445p.

11. Gonçalves LO, Ferreira CB, Zanini DS, Vasconcelos CLB, Gonçalves SSS. Coping em pacientes crônicos, cuidadores e profissionais de saúde. Rev SPAGESP [Internet]. 2015 [citado em 19 jun 2019]; 16(1):107-21. Disponível em: http://pepsic.bvsalud.org/pdf/rspagesp/v16n1/v16n1a09.pdf

12. Friedrich F, Aparecida M, Uyeda M. Fatores que interferem na adesão ao tratamento da Diabetes Mellitus Gestacional. Rev Saúde Desenvolv. [Internet]. 2019 [citado em 22 nov 2019]; 13(14):84-99. Disponível

em: https://www.uninter.com/revistasaude/index.php/saudeDesenvolvimento/article/view/1018 13. Víctora CG, Knauth DR, Hassen MN. Pesquisa qualitativa em saúde. Porto Alegre: Tomo Editorial; 2000. 134p

14. McNamee S, Hosking DM. Research and social change: a relational constructionist approach. New York: Routledge; 2012. 154p

15. Spink MJP. Desvendando as teorias implícitas: uma metodologia de análise das representações sociais. In: Guareschi P, Jovchelovitch S, organizadores. Petrópolis, RJ: Vozes; 2000. p.117-45. (Textos em representações sociais)

16. Draffin CR, Alderdice FA, McCance DR, Maresh M, Harper R, McSorley O, et al. Exploring the needs, concerns and knowledge of women diagnosed with gestational diabetes: a qualitative study. Midwifery [Internet]. 2016 [citado em 22 nov 2019]; 40:141-7. DOI: http://dx.doi.org/10.1016/j.midw.2016.06.019

17. Persson M, Winkvist A, Mogren I. 'From stun to gradual balance' - women's experiences of living with gestational diabetes mellitus. Scand J Caring Sci [Internet]. 2010 [citado em 22 nov 2019]; 24(3): 454-62. DOI: https://doi.org/10.1111/j.1471-6712.2009.00735.x

18. Ge L, Wikby K, Rask M. Lived experience of women with gestational diabetes mellitus living in China: a qualitative interview study. BMJ Open [Internet]. 2017 [citado em 05 fev 2020]; 7:e017648. DOI: http://dx.doi.org/10.1136/bmjopen- 2017- 017648

19. Mançú TS, Almeida OSC. Conhecimentos e sentimentos das gestantes diabéticas sobre a diabetes mellitus gestacional e tratamento. Rev Enferm UFPE on line [Internet]. 2016 [citado em 14 jun 2019]; 10(3):1474-82. DOI: https://doi.org/10.5205/1981-8963v10i3a11089p1474-1482-2016

20. Ferreira SV, Soares MC, Alves CN, Cecagno S, Soares TM, Braga LR. Cuidado de enfermagem na ótica das gestantes de alto risco. REFACS [Internet]. 2019 [citado em 14 jun 2019]; 7(2):143-50. DOI: https://doi.org/10.18554/refacs.v7i2.3410

21. Karsten LF, Souza DL, Vieira MR, Silva JC. Influência do diagnóstico de diabetes mellitus gestacional na qualidade de vida da gestante. Saúde e Pesqui. [Internet]. 2016 [citado em 05 fev 2020]; 9(1):7-14. DOI: http://dx.doi.org/10.177651/1983-1870.2016v9n1p7-14

22. Cunha ACB, Marques CD, Lima CP. Rede de apoio e suporte emocional no enfrentamento da diabetes mellitus por gestantes. Mudanças [Internet]. 2017 [citado em 05 fev 2020]; 25(2):3543. DOI: http://dx.doi.org/10.15603/2176-1019/mud.v25n2p35-43

23. Borges MCB, Souza Júnior JÁ, Ribeiro LAN, Ribeiro MF, Oliveira PC, Reis RMS, et al. 0 conhecimento das gestantes sobre o diabetes mellitus gestacional em unidade de pré natal no sul de Minas Gerais. Arch Health Invest. [Internet]. 2017 [citado em 05 fev 2020]; 6(8):348-51. DOI: http://dx.doi.org/10.21270/archi.v6i8.2089

24. Souza JS, Takemoto AY. Diabetes mellitus gestacional e as dificuldades para o autocuidado. Rev Parana Enferm. [Internet]. 2018 [citado em 22 nov 2019]; 1(1):37-46. Disponível em: http://www.fafiman.br/seer/index.php/REPEN/article/view/461/483 
25. Schmalfuss JM, Bonilha ALL. Implicações das restrições alimentares na vida diária de mulheres com diabete melito gestacional Rev Enferm UERJ [Internet]. 2015 [citado em 31 jul 2019]; 23(1):39-44. DOI: http://dx.doi.org/10.12957/reuerj.2015.5712

26. Santos ACR. Auto-eficácia, coping e expectativas da prematuridade durante a gravidez. [dissertação]. Lisboa, Portugal: Instituto Universitário de Ciências Psicológicas, Sociais e da Vida; 2009. 147p.

27. Ramos L, Ferreira EAP. Emotional factors, life quality and adhesion of treatment in adult with diabetes type 2. J Hum Growth Develop. [Internet]. 2011 [citado em 15 maio 2019]; 21(3):867-77. Disponível em: http://pepsic.bvsalud.org/scielo.php?script=sci_arttext\&pid=S0104-12822011000300013

\section{CONTRIBUIÇÕES}

Maira Julyê Mota Fernandes contribuiu na concepção, coleta e análise dos dados e, redação. Cintia Bragheto Ferreira participou na análise dos dados, redação e revisão.

\section{Como citar este artigo (Vancouver)}

Fernandes MJM, Ferreira CB. Percepções de gestantes com diabetes mellitus gestacional: diagnóstico, hospitalização e enfrentamentos. REFACS [Internet]. 2020 [citado em inserir dia, mês e ano de acesso]; 8(3):435-445. Disponível em: inserir link de acesso. DOI: inserir link do DOI.

\section{Como citar este artigo (ABNT)}

FERNANDES, M. J. M.; FERREIRA, C. B. Percepções de gestantes com diabetes mellitus gestacional: diagnóstico, hospitalização e enfrentamentos. REFACS, Uberaba, MG, v. 8, n. 3, p. 435-445, 2020. Disponível em: inserir link de acesso. Acesso em: inserir dia, mês e ano de acesso. DOI: inserir link do DOI.

\section{Como citar este artigo (APA)}

Fernandes, M.J.M. \& Ferreira, C.B. (2020). Percepções de gestantes com diabetes mellitus gestacional: diagnóstico, hospitalização e enfrentamentos. REFACS, 8(3), 435-445. Recuperado em: inserir dia, mês e ano de acesso de inserir link de acesso. DOI: inserir link do DOI. 